\title{
Pengendalian Longsor di Daerah Desa Sumberharjo, Kecamatan Prambanan, Kabupaten Sleman, Daerah Istimewa Yogyakarta
}

\author{
Controlling Landslide in Area of Sumberharjo Village, Prambanan \\ Subdistrict, Regency of Sleman, Daerah Istimewa Yogyakarta \\ Dian Hudawan Santoso*, Eni Muryani, Adilla Zahra Permatasari \\ Teknik Lingkungan, Fakultas Teknologi Mineral \\ Universitas Pembangunan Nasional "Veteran" Yogyakarta-INDONESIA \\ *corresponding author, email: hudageo@gmail.com
}

Manuscript received: 03-07-2019. Accepted: 25-12-2019

\begin{abstract}
ABSTRAK
Tanggal 28 November 2017 di Daerah Desa Sumberharjo, Kecamatan Prambanan, Kabupaten Sleman, Daerah Istimewa Yogyakarta terjadi longsor. Lahan sisa longsor yang curam tersusun atas batuan dengan adanya perkembangan kekar. Jarak permukiman terdekat yaitu $8 \mathrm{~m}$ dari kepala lereng. Tujuan dari penelitian ini untuk mengetahui tingkat kerawanan longsor berdasarkan faktor pengontrol dan faktor pemicu dan menentukan teknik rekayasa lereng dalam pengendalian area longsor. Metode yang digunakan dalam pengumpulan data adalah metode survei dan pemetaan lapangan. Pemetaan dilakukan terhadap faktor pengontrol pada parameter kerawanan yaitu kemiringan lereng, tekstur tanah, ketebalan solum tanah, pelapukan batuan, kapasitas infiltrasi, dan penggunaan lahan. Parameter curah hujan sebagai faktor pemicu dilakukan analisis data sekunder. Zonasi kerawanan longsor didapatkan dengan metode pengharkatan berdasarkan parameter tersebut. Penentuan rekayasa lereng dilakukan dengan pengambilan sampel tanah sebanyak 3 sampel untuk tahap analisis laboratorium. Teknik pengambilan sampel tanah yaitu purposive sampling berdasarkan kemiringan lereng dan tekstur tanah di lahan sisa longsor. Hasil laboratorium digunakan untuk perhitungan kestabilan lereng menggunakan Metode Janbu. Seluruh data yang didapatkan dilakukan analisis sesuai kondisi rona lingkungan. Hasil penelitian menunjukkan bahwa, daerah penelitian terdiri dari 3 zona kerawanan longsor yaitu tingkat kerawanan rendah dengan luas $2.756,18 \mathrm{~m}^{2}$, tingkat kerawanan sedang dengan luas $61.556,92 \mathrm{~m}^{2}$, dan tingkat kerawanan tinggi dengan luas $6.298,90 \mathrm{~m}^{2}$. Nilai faktor keamanan lereng lahan sisa longsor yaitu 0,944 yang termasuk ke dalam klasifikasi tidak stabil. Pengendalian longsor dilakukan pada zona dengan tingkat kerawanan tinggi yang berada di lahan sisa longsor dengan pembuatan teras, pembuatan dinding penahan dengan tipe gravity wall, pembuatan drainase permukaan, dan penanaman pohon jati dengan kombinasi rumput akar wangi. Upaya pengendalian tersebut meningkatkan nilai faktor keamanan lereng menjadi 1,33 .
\end{abstract}

Kata kunci: Janbu; Keamanan; Kerawanan; Lereng 


\begin{abstract}
The landslide occurred in area of Sumberharjo Village, Prambanan Subdistrict, Regency of Sleman, Daerah Istimewa Yogyakarta Province on $28^{\text {th }}$ November 2018. The landslide area have a steep slope and complex geological conditions like a cracks. The closest settlement is located $8 \mathrm{~m}$ far from the landslide area. The purpose of the research is to determine the vulnerability of landslide zonation level based on control and trigger factor and to design technique of controlling landslide area.The methodology used in this research are survey method and field mapping. Mapping method based on the control factor which has parameter like slope, soil texture, soil thickness, weathering of rock, infiltration capacity and land use. The rainfall level parameter as a trigger factor are analyzed by secondary data. Vulnerability of landslide zonation level zoning is obtained by the scoring method based on these parameters. Determination of slope engineering by taking 3 samples of soil for laboratory analysis. The soil sampling technique is purposive sampling which is based on slope and soil texture in landslide area. The laboratory results are used to calculate slope stability using the Janbu Method. All data obtained are analyzed based on environmental conditions. The research area has 3 landslide vulnerability zones: low vulnerability level with $2756.18 \mathrm{~m}^{2}$ of area, moderate vulnerability level with $61556.92 \mathrm{~m}^{2}$ of area, and high vulnerability level with $6298,90 \mathrm{~m}^{2}$ of area. The value of safety factor on landslide area is 0.94 which is classified as unstable. Lanslide management applied in area which has high vulnerability level on landslide area by making a bench that combined with gravity wall, surface drainage, and vegetation planting such as Jati and vertiver grass. The control effort increases the value of the slope safety factor to 1.33 .
\end{abstract}

Keyword: Janbu; Safety; Slop; Vulnerability

\title{
PENDAHULUAN
}

Jumlah penduduk di Indonesia mengalami peningkatan dari tahun ke tahun. Presentase distribusi khususnya di Kabupaten Sleman, Daerah Istimewa Yogyakarta memiliki nilai sebesar 31,62\% (Badan Pusat Statistik, 2019). Kondisi tersebut menjadikan alasan masyarakat melakukan eksploitasi lahan secara sembarangan sehingga, mengubah fungsi lahan. Masyarakat tidak memperhatikan tata guna lahan, seperti lahan yang seharusnya sebagai perkebunan dan hutan menjadi lahan untuk permukiman. Perubahan fungsi lahan yang tidak sesuai peruntukannya dapat mengganggu kondisi geofisik-kimia dari lahan. Pembangunan permukiman di daerah dengan lereng yang umumnya terjal meningkatkan ancaman bahaya bencana bagi masyarakat. Dampak dari perlakuan lahan yang tidak sesuai dapat mengakibatkan gerakan massa tanah dan batuan. Gerakan massa tanah dan batuan merupakan gerakan menuruni lereng oleh massa tanah atau batuan penyusun lereng, ataupun campuran keduanya sebagai bahan rombakan, akibat dari terganggunya stabilitas lereng tersebut (Karnawati, 2005).

Gerakan massa tanah dan batuan dipengaruhi oleh faktor pengontrol dan faktor pemicu. Faktor pengontrol merupakan faktor yang menyebabkan lereng menjadi rentan atau siap bergerak dan berasal dari kondisi alamiah, antara lain kemiringan lereng, geomorfologi, stratigrafi, struktur geologi, dan penggunaan lahan. Faktor pemicu merupakan suatu proses yang menjadikan lereng dalam kondisi kritis dan kemudian bergerak dan berasal dari kondisi alamiah maupun non alamiah. Proses yang dapat memicu lereng untuk bergerak yaitu infiltrasi hujan, getaran, dan perubahan tata guna lahan oleh aktivitas manusia (Karnawati, 2005).

Varnes (1978) dalam Zakaria (2009), mengklasifikasikan gerakan massa tanah dan batuan dibagi menjadi, jatuhan (falls), robohan (topples), longsoran (slides), sebaran lateral (lateral spreaings), dan aliran (flows). Klasifikasi tipe gerakan massa tanah dan batuan menurut Hunt (2007) dibagi berdasarkan jenis pergerakan, bentuk bidang keruntuhan, koherensi massa tanah dan batuan, konstitusi pergerakan massa tanah dan batuan, struksur geologi, perpindahan massa, tipe material yang bergerak, dan kecepatan pergerakan massa. 
Tingkat kerawanan merupakan ukuran yang menyatakan tinggi rendahnya atau besar kecilnya kemungkinan suatu kawasan atau zona dapat mengalami bencana longsor, serta besarnya korban dan kerugian bila terjadi bencana longsor yang diukur berdasarkan tingkat kerawanan fisik alamiah dan tingkat kerawanan karena aktifitas manusia (Permen PU No. 22/PRT/M/2007). Tingkat kerawanan fisik alamiah terdiri dari kemiringan lereng, kondisi tanah, batuan penyusun, curah hujan, perairan lereng, dan kegempaan. Tingkat kerawanan longsor merupakan bentuk ketidakstabilan pada lereng, sehingga perlu dikaji dengan analisis kestabilan lereng.

Salah satu metode dalam analisis kestabilan lereng yatu Metode Janbu yang disederhanakan. Metode Janbu yang disederhanakan menggunakan persamaan kesetimbangan gaya horizontal untuk memperoleh nilai faktor keamanan. Hal itu tidak termasuk gaya di dalam irisan saat analisis tetapi dalam perhitungannya menggunakan faktor koreksi. Faktor koreksi yang digunakan terkait dengan kohesi, sudut geser dalam, dan bentuk dari bidang longsorsan (Janbu dkk., 1956 dalam Rahman 2012). Menurut Departemen Pekerjaan Umum (2005), metode Janbu yang disederhanakan digunakan pada daerah lereng dengan tanah sebagian besar berupa tanah residual dengan bentuk bidang gelincir rotasi maupun translasi.

Gerakan massa tanah dan batuan yang umumnya terjadi yaitu longsor. Longsor adalah suatu proses perpindahan massa tanah atau batuan dengan arah miring dari kedudukan semula, sehingga terpisah dari massa yang mantap, karena pengaruh gravitasi; dengan jenis gerakan berbentuk rotasi dan translasi (Permen PU No. 22/PRT/M/2007). Longsor terjadi di Daerah Desa Sumberharjo, Kecamatan Prambanan, Kabupaten Sleman, Provinsi Daerah Istimewa Yogyakarta pada tanggal 28 November 2017 setelah adanya intensitas hujan yang tinggi dan berlangsung selama tiga hari berturut-turut. Terdapatnya rekahan-rekahan pada batuan yang menerus menjadi alasan terjadinya longsor. Longsor berdampak kerusakan pada tiga rumah warga dan kandang sapi yang berada di bawah lereng. Bencana ini tidak menimbulkan korban jiwa. Kondisi lahan sisa longsor memiliki kemiringan lereng rata-rata $40^{\circ}$ dan jarak permukiman terdekat dengan lahan sisa longsor bagian kepala lereng yaitu 8 meter. Tujuan dari penelitian ini untuk mengetahui tingkat kerawanan longsor berdasarkan faktor pengontrol dan faktor pemicu dan menentukan teknik rekayasa lereng dalam pengendalian daerah lahan sisa longsor.

\section{BAHAN DAN METODE}

Penelitian dilakukan dengan metode survei dan pemetaan secara langsung di lapangan, metode analisis laboratorium, metode pengharkatan, metode analisis deskriptif dan analisis matematis. Metode survei dan pemetaan dilakukan dengan tujuan untuk mendapatkan data mengenai kondisi daerah penelitian yang digunakan untuk mendukung penelitian termasuk proses wawancara. Data yang berupa komponen lingkungan didapatkan dengan cara pengukuran dan pengamatan langsung di lapangan. Metode analisis laboratorium digunakan untuk mengetahui sifat fisik dan mekanika tanah untuk menentukan bentuk pengendalian terkait longsor yang diteliti dengan pengambilan sampel tanah. Metode pengharkatan dilakukan untuk mengkaji tingkat kerawanan longsor dan pembagian zonas rawan longsor. Analisis secara kuantitatif dilakukan dengan perhitungan kestabilan lereng dengan Metode Janbu yang disederhanakan untuk mengetahui faktor keamanan guna menentukan upaya pengendalian dan pengelolaan longsor. Analisis secara deskriptif dilakukan terhadap seluruh 
komponen lingkungan dan dikaitkan terhadap hasil analisis kestabilan lereng dan hasil zonasi kerawanan longsor.

Parameter yang digunakan dalam analisis dengan metode pengharkatan untuk menentukan zonasi tingkat kerawanan longsor yaitu curah hujan yang diperoleh dari data curah hujan Stasiun Prambanan tahun 2009-2018. Sedangkan parameter kemiringan lereng, tekstur tanah, ketebalan solum tanah, tingkat pelapukan batuan, penggunaan lahan, dan kapasitas infiltrasi diperoleh dari pemetaan secara langsung di lapangan. Nilai harkat setiap parameter kerawanan dapat dilihat pada Tabel 1.

Tabel 1. Pengharkatan Parameter Kerawanan Longsor (Dibyosaputro, 1998)

\begin{tabular}{|c|c|c|c|c|}
\hline \multirow{2}{*}{ No } & \multirow{2}{*}{ Faktor Pengaruh } & \multirow{2}{*}{ Parameter } & \multicolumn{2}{|c|}{ Harkat } \\
\hline & & & $\max$ & $\min$ \\
\hline 1 & Iklim & Curah hujan & 5 & 1 \\
\hline 2 & Lereng & Kemiringan lereng & 5 & 1 \\
\hline 3 & Geologi & Tingkat pelapukan batuan & 5 & 1 \\
\hline 4 & Tanah & $\begin{array}{c}\text { Tekstur tanah } \\
\text { Ketebalan tanah } \\
\text { Kapasitas infiltrasi }\end{array}$ & $\begin{array}{l}5 \\
5 \\
5\end{array}$ & $\begin{array}{l}1 \\
1 \\
1\end{array}$ \\
\hline 5 & Penggunaan lahan & Penggunaan lahan & 5 & 1 \\
\hline \multicolumn{3}{|c|}{ Jumlah } & 35 & 7 \\
\hline
\end{tabular}

Untuk mendapatkan interval kelas kerawanan dilakukan perhitungan:

$$
\text { Interval Kelas Kerawanan }=\frac{\sum \text { Skor Maksimal }-\Sigma \text { Skor Minimal }}{5}
$$

Berdasarkan hasil perhitungan interval kelas kerawanan, maka ditentukan kelas tingkat kerawanan longsor yang dapat dilihat pada Tabel 2.

Tabel 2. Kelas Tingkat Kerawanan Longsor (Dibyosaputro, 1998)

\begin{tabular}{cccc}
\hline No & Interval Total Harkat & Kriteria Kerawanan & Kelas \\
\hline 1 & $7-12$ & Sangat rendah & 1 \\
2 & $13-18$ & Rendah & 2 \\
3 & $19-23$ & Sedang & 3 \\
4 & $24-29$ & Tinggi & 4 \\
5 & $30-35$ & Sangat tinggi & 5 \\
\hline
\end{tabular}

Analisis matematis dilakukan dengan analisis kestabilan lereng dengan Metode Janbu yang disederhanakan yang bertujuan untuk mengetahui nilai faktor keamanan lereng agar memperoleh upaya pengendalian dan pengelolaan yang tepat. 
Nilai faktor keamanan dapat ditentukan dengan rumus perhitungan:

$$
F=\frac{\tau_{a}}{\tau_{m}}
$$

Keterangan:

$\tau_{\mathrm{a}}=$ kekuatan geser material yang tersedia

$\tau_{\mathrm{m}}=$ kekuatan geser material yang diperlukan agar tepat setimbang.

$$
F=\frac{\left.\sum_{i=1}^{n} c^{n} \beta+(N-u \beta) \tan \phi^{\sigma}\right) \cos \alpha}{\sum_{i=1}^{n}(N \sin \alpha+k W)+A}
$$

Keterangan:

$$
\begin{aligned}
& N=\text { gaya normal } \\
& c^{\prime}=\text { kohesi efektif } \\
& \varphi^{\prime}=\text { sudut gesek efektif } \\
& \mathrm{u}=\text { tekanan air pori }
\end{aligned}
$$

Hasil perhitungan faktor keamanan dilakukan penentuan klasifikasi lereng yang dapat dilihat pada Tabel 3.

Tabel 3. Klasifikasi Nilai Faktor Keamanan

\begin{tabular}{cc}
\hline Nilai factor Keamanan & Kejadian atau Intensitas Longsoran \\
\hline FK $<1,07$ & Tidak stabil \\
FK $=1,07-1,25$ & Kritis \\
FK $>1,25$ & Stabil \\
\hline
\end{tabular}

HASIL DAN PEMBAHASAN

Hasil tumpang susun dan pengharkatan menghasilkan tingkat kerawanan longsor di daerah penelitian yang terbagi menjadi 3 klasifikasi, yaitu tingkat kerawanan rendah dengan luasan $2756,18 \mathrm{~m}^{2}$, tingkat kerawanan sedang dengan luasan $61556,92 \mathrm{~m}^{2}$, dan tingkat kerawanan tinggi dengan luasan $6298,90 \mathrm{~m}^{2}$. Zona kerawanan tinggi dikontrol oleh solum tanah yang cenderung lebih tebal dibandingkan solum di sekitarnya dan memiliki kategori air hujan yang sedang. Tata guna lahan berupa tegalan dan lahan permukiman mempengaruhi kerawanan longsor tingkat tinggi. Zona kerawanan tinggi yang berada di bagian lereng longsoran dikontrol oleh kemiringan lereng terjal $\left(39^{\circ}-42^{\circ}\right)$ dan lahan tersebut digunakan sebagai lahan tegalan.

Sebagaimana Tabel 4 diketahui bahwa secara keseluruhan tingkat kerawanan di daerah penelitian bervariasi antara rendah, sedang dan tinggi. Hal ini diperoleh dari jumlah skor total setelah setiap parameter diberi nilai skor masing-masing. Tingkat kerawanan rendah diperoleh 
total skor antara 16-18. Tingkat kerawanan sedang diperoleh skor antara 19-23 sedangkan tongkat kerawanan tinggi diperoleh nilai 24 dan 25.

Tabel 4. Skor Pada Harkat Setiap Parameter

\begin{tabular}{|c|c|c|c|c|c|c|c|c|}
\hline \multirow[b]{2}{*}{$\begin{array}{l}\text { Curah } \\
\text { Hujan }\end{array}$} & \multicolumn{5}{|c|}{ Skor Pada Harkat Setiap Parameter } & \multirow[b]{2}{*}{$\begin{array}{c}\text { Kapasitas } \\
\text { Infiltrasi }\end{array}$} & \multirow[b]{2}{*}{$\begin{array}{l}\text { Total } \\
\text { Skor }\end{array}$} & \multirow[b]{2}{*}{$\begin{array}{c}\text { Tingkat } \\
\text { Kerawanan }\end{array}$} \\
\hline & $\begin{array}{l}\text { Kemiringan } \\
\text { Lereng }\end{array}$ & $\begin{array}{l}\text { Tekstur } \\
\text { Tanah }\end{array}$ & $\begin{array}{c}\text { Ketebalan } \\
\text { Solum }\end{array}$ & $\begin{array}{c}\text { Pelapukan } \\
\text { Batuan }\end{array}$ & $\begin{array}{c}\text { Penggunaan } \\
\text { Lahan }\end{array}$ & & & \\
\hline 2 & 3 & 4 & 2 & 3 & 3 & 1 & 18 & Rendah \\
\hline 2 & 3 & 4 & 2 & 3 & 3 & 1 & 18 & Rendah \\
\hline 2 & 3 & 4 & 2 & 3 & 3 & 1 & 18 & Rendah \\
\hline 2 & 1 & 4 & 2 & 3 & 3 & 1 & 16 & Rendah \\
\hline 2 & 2 & 4 & 2 & 3 & 3 & 1 & 17 & Rendah \\
\hline 2 & 2 & 4 & 2 & 3 & 3 & 1 & 17 & Rendah \\
\hline 2 & 3 & 4 & 2 & 3 & 3 & 1 & 18 & Rendah \\
\hline 2 & 3 & 4 & 2 & 3 & 3 & 1 & 18 & Rendah \\
\hline 2 & 3 & 4 & 1 & 3 & 3 & 1 & 17 & Rendah \\
\hline 2 & 4 & 4 & 1 & 3 & 3 & 1 & 18 & Rendah \\
\hline 2 & 3 & 4 & 2 & 3 & 3 & 5 & 22 & Sedang \\
\hline 2 & 4 & 4 & 2 & 3 & 3 & 5 & 23 & Sedang \\
\hline 2 & 4 & 4 & 2 & 3 & 3 & 1 & 19 & Sedang \\
\hline 2 & 3 & 4 & 2 & 3 & 3 & 5 & 22 & Sedang \\
\hline 2 & 1 & 4 & 2 & 3 & 3 & 5 & 20 & Sedang \\
\hline 2 & 2 & 4 & 2 & 3 & 3 & 5 & 21 & Sedang \\
\hline 2 & 3 & 4 & 2 & 3 & 3 & 5 & 22 & Sedang \\
\hline 2 & 3 & 4 & 1 & 3 & 3 & 5 & 21 & Sedang \\
\hline 2 & 3 & 4 & 3 & 3 & 3 & 5 & 23 & Sedang \\
\hline 2 & 2 & 4 & 3 & 3 & 3 & 5 & 22 & Sedang \\
\hline 2 & 3 & 4 & 3 & 3 & 3 & 5 & 23 & Sedang \\
\hline 2 & 3 & 4 & 3 & 3 & 3 & 1 & 19 & Sedang \\
\hline 2 & 2 & 4 & 3 & 3 & 4 & 5 & 23 & Sedang \\
\hline 2 & 2 & 4 & 3 & 3 & 4 & 5 & 23 & Sedang \\
\hline 2 & 3 & 4 & 2 & 3 & 4 & 5 & 23 & Sedang \\
\hline 2 & 2 & 4 & 3 & 3 & 4 & 5 & 23 & Sedang \\
\hline 2 & 3 & 4 & 2 & 3 & 5 & 1 & 20 & Sedang \\
\hline 2 & 3 & 4 & 2 & 3 & 5 & 1 & 20 & Sedang \\
\hline 2 & 4 & 4 & 2 & 3 & 5 & 1 & 21 & Sedang \\
\hline 2 & 3 & 4 & 2 & 3 & 5 & 1 & 20 & Sedang \\
\hline 2 & 3 & 4 & 2 & 3 & 5 & 1 & 20 & Sedang \\
\hline 2 & 1 & 4 & 2 & 3 & 5 & 5 & 22 & Sedang \\
\hline 2 & 2 & 4 & 2 & 3 & 5 & 1 & 19 & Sedang \\
\hline 2 & 3 & 4 & 2 & 3 & 5 & 1 & 20 & Sedang \\
\hline 2 & 3 & 4 & 1 & 3 & 5 & 5 & 23 & Sedang \\
\hline 2 & 3 & 4 & 1 & 3 & 5 & 1 & 19 & Sedang \\
\hline 2 & 3 & 4 & 1 & 3 & 5 & 1 & 19 & Sedang \\
\hline 2 & 4 & 4 & 1 & 3 & 5 & 1 & 20 & Sedang \\
\hline
\end{tabular}




\begin{tabular}{|c|c|c|c|c|c|c|c|c|}
\hline \multirow[b]{2}{*}{$\begin{array}{l}\text { Curah } \\
\text { Hujan }\end{array}$} & \multirow[b]{2}{*}{$\begin{array}{c}\text { Kemiringan } \\
\text { Lereng }\end{array}$} & \multicolumn{4}{|c|}{ Skor Pada Harkat Setiap Parameter } & \multirow[b]{2}{*}{$\begin{array}{c}\text { Kapasitas } \\
\text { Infiltrasi }\end{array}$} & \multirow[b]{2}{*}{$\begin{array}{l}\text { Total } \\
\text { Skor }\end{array}$} & \multirow[b]{2}{*}{$\begin{array}{c}\text { Tingkat } \\
\text { Kerawanan }\end{array}$} \\
\hline & & $\begin{array}{l}\text { Tekstur } \\
\text { Tanah }\end{array}$ & $\begin{array}{c}\text { Ketebalan } \\
\text { Solum }\end{array}$ & $\begin{array}{c}\text { Pelapukan } \\
\text { Batuan }\end{array}$ & $\begin{array}{c}\text { Penggunaan } \\
\text { Lahan }\end{array}$ & & & \\
\hline 2 & 3 & 4 & 3 & 3 & 5 & 1 & 21 & Sedang \\
\hline 2 & 1 & 4 & 3 & 3 & 5 & 5 & 23 & Sedang \\
\hline 2 & 1 & 4 & 3 & 3 & 5 & 1 & 19 & Sedang \\
\hline 2 & 4 & 4 & 3 & 3 & 5 & 1 & 22 & Sedang \\
\hline 2 & 3 & 4 & 3 & 3 & 5 & 1 & 21 & Sedang \\
\hline 2 & 3 & 4 & 3 & 3 & 4 & 5 & 24 & Tinggi \\
\hline 2 & 3 & 4 & 3 & 3 & 4 & 5 & 24 & Tinggi \\
\hline 2 & 3 & 4 & 3 & 3 & 5 & 5 & 25 & Tinggi \\
\hline 2 & 2 & 4 & 3 & 3 & 5 & 5 & 24 & Tinggi \\
\hline 2 & 2 & 4 & 3 & 3 & 5 & 5 & 24 & Tinggi \\
\hline 2 & 2 & 4 & 3 & 3 & 5 & 5 & 24 & Tinggi \\
\hline 2 & 3 & 4 & 2 & 3 & 5 & 5 & 24 & Tinggi \\
\hline 2 & 3 & 4 & 2 & 3 & 5 & 5 & 24 & Tinggi \\
\hline 2 & 4 & 4 & 2 & 3 & 5 & 5 & 25 & Tinggi \\
\hline 2 & 3 & 4 & 2 & 3 & 5 & 5 & 24 & Tinggi \\
\hline 2 & 3 & 4 & 3 & 3 & 5 & 5 & 25 & Tinggi \\
\hline
\end{tabular}

Sumber : Analisis data lapangan, 2018

Terdapatnya faktor pengontrol di luar 7 parameter yang digunakan dalam pengharkatan juga dapat memicu terjadinya longsor, misalnya perkembangan kekar. Kekar-kekar pada batuan di daerah penelitian dapat memotong perlapisan batuan yang menyusun dan berperan dalam masuknya air hujan ke dalam celah-celah batuan, sehingga dapat menurunkan kekompakan pada batuan penyusun. Longsor yang terjadi dikontrol oleh bentuklahan berupa lereng punggungan yang memiliki kemiringan lereng terjal dengan nilai kemiringan $16-22^{\circ}$ (29.63-40\%). Lereng dengan kategori terjal memiliki gaya tarik yang besar dari topografi tinggi ke topografi rendah. Material yang terdapat di atas lereng dapat berupa tanah. Rata-rata ketebalan solum tanah di daerah penelitian yaitu $20 \mathrm{~cm}$ hingga $90 \mathrm{~cm}$. Semakin tebal tanah artinya akan semakin banyak air hujan yang akan masuk ke dalam tanah. Tanah di daerah penelitian memiliki tekstur secara umum yaitu lempung pasiran. Tanah akan mengalami retakretak pada saat musim kemarau karena memiliki sifat kohesif. Nilai kapasitas infiltrasi yaitu $0.3 \mathrm{~cm} / \mathrm{jam}$ yang menunjukkan laju yang sangat lambat dikarenakan ikatan antar partikel pada tanah sangat kuat dan air hujan akan menggenang dan hanya masuk ke dalam tanah dengan kedalaman dangkal.

Jenis batuan di daerah penelitian merupakan breksi tuff dan mengalami pelapukan pada tingkat lanjut yang tersebar secara merata. Kedudukan batuan breksi tuff yaitu N $140^{\circ} \mathrm{E} / 22^{\circ}$ dengan arah kemiringan lapisan yaitu ke arah Barat Daya. Batuan breksi tuff di daerah penelitian memiliki arah kemenerusan perlapisan yaitu ke arah Tenggara-Barat Laut. Arah kemiringan lapisan batuan memiliki arah yang cenderung sama dengan arah longsoran yaitu $\mathrm{N}$ $285^{\circ} \mathrm{E}$ menunjukan bahwa longsoran yang terjadi dikontrol oleh perlapisan dari batuan penyusun lereng itu sendiri. Kondisi struktur geologi berupa kekar dengan arah umum $\mathrm{N} 163^{\circ} \mathrm{E}$ / $86^{\circ}$ dan memiliki arah kemenerusan ke arah Tenggara-Barat Laut. Arah kemenerusan kekar 
di lapangan menunjukkan peran kekar dalam memotong batuan penyusunnya dengan hasil arah potongan yang sama dengan arah longsoran, sehingga keterdapatan kekar di daerah penelitian memiliki peran dalam terjadinya longsor. Tata guna lahan yang mendominasi yaitu kebun campur, namun perubahan fungsi lahan oleh manusia di tepi lereng menjadi area permukiman meningkatkan faktor untuk menggerakkan lereng karena beban yang semakin besar. Perubahan tata guna lahan pada lahan sisa longsoran menjadi lahan tegalan akan meningkatkan ancaman longsor bagi masyarakat sekitar.

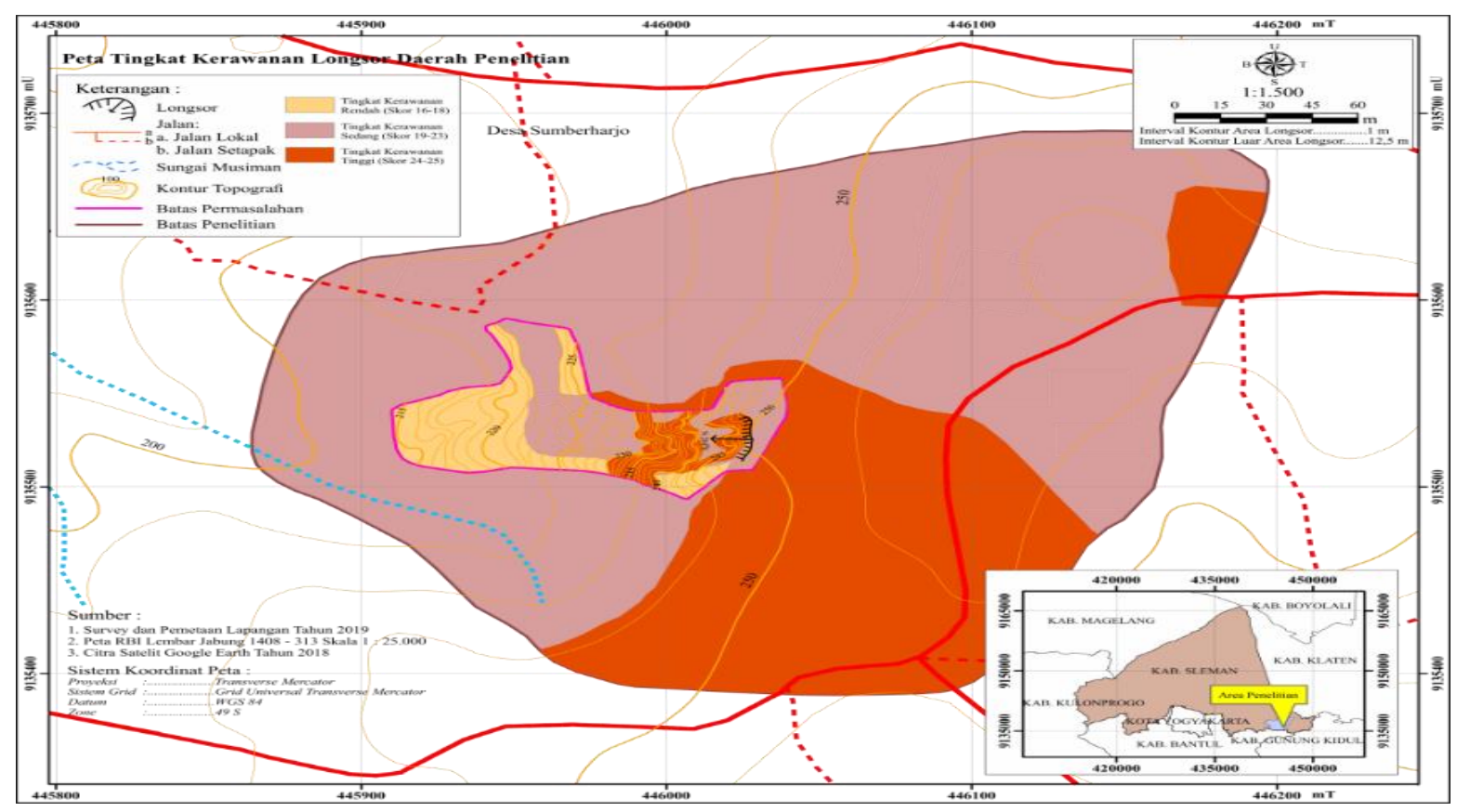

Gambar 1. Zonasi Tingkat Kerawanan Longsor di Daerah Penelitian Sumber: Penulis (2019)

Sebaran zona kerawanan di daerah penelitian dapat dilihat pada Gambar 1. Terlihat bahwa secara umum daerah penelitian luas zona tingkat kerawanan sedang jauh lebih dominan dibandingkan dengan luas zona tingkat kerawanan tinggi dan zona tingkat kerawanan rendah. Zona tingkat kerawanan tinggi lebih luas dibandingkan dengan zona tingkat kerawanan rendah. Zona tingkat kerawanan tinggi secara lokasi berada dibagian selatan daerah penelitian dan sebagain kecil berada di sebelah timur laut dari lokasi tanah longor sedangkan zona tingkat kerawanan rendah berada di sebelah barat lokasi terjadinya longsor dengan luasanya yang tidak terlalu dominan.

Sebagaimana ditunjukkan dalam Gambar 2, diketahui model 3D longsorang di daerah penelitian. Posisi bagian atas area longsor didominasi oleh bentuk lahan punggungan bukti dengan topografi lerang yang terjal, pada gambar ditunjukkan dengan warna merah yang lebih gelap. Pada area yang berwarna biru merupakan daerah yang secara topografi lebih rendah dan lebih datar sehingga lokasi ini diperkirakan dapat menerima efek gerakan masa tanah ketika terjadi longsoran. 


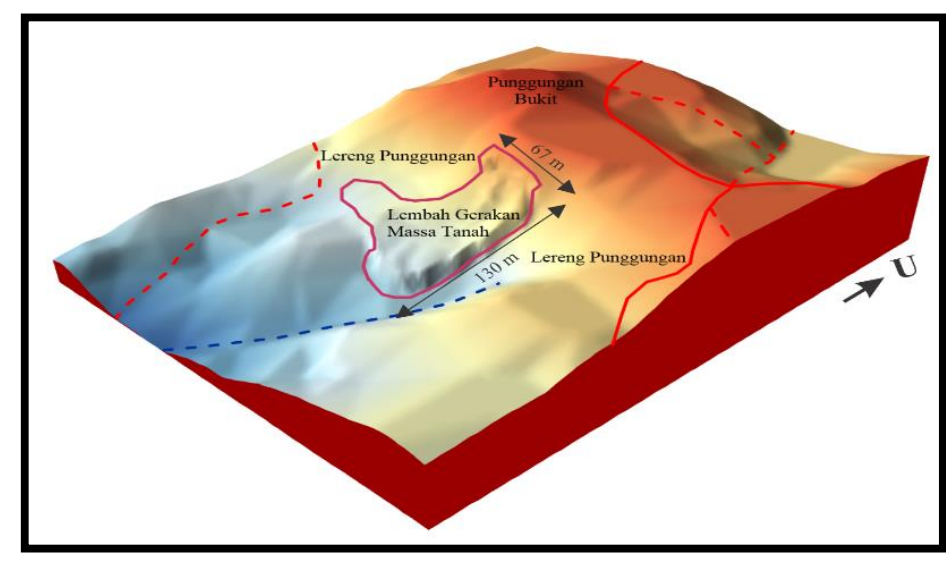

Gambar 1. Model 3D Lahan Longsoran di Daerah Penelitian Sumber: Analisis (2019)

Zona kerawanan tinggi khususnya yang berada pada area longsor dilakukan analisis kestabilan lereng dengan hasil faktor keamanan 0.94 yang termasuk ke dalam klasifikasi tidak stabil. Nilai faktor keamnaan lereng yang tidak stabil dikontrol oleh faktor kemiringan lereng sebesar $40^{\circ}$ yang termasuk ke dalam klasifikasi terjal menurut Dibyosaputro (1998). Kemiringan lereng yang terjal sesuai dengan bentuklahan di daerah penelitian yang merupakan lereng punggungan. Faktor pengontrol lerereng lain yang mengakibatkan lereng tidak stabil yaitu sifat fisik dan mekanik dari tanah penyusun lereng itu sendiri. Kadar air tanah yang sangat dipengaruhi oleh curah hujan di daerah penelitian yang termasuk kategori sedang dapat mengubah nilai kohesi dan sudut geser dalam menjadi kecil yang meningkatkan gaya geser tanah. Kadar air tanah yang tinggi juga akan menurunkan nilai bobot isi tanah yang menjadikan beban lereng semakin meningkat dan memperbesar gaya pendorong pada lereng. Rembesan yang berada cenderung di bagian atas lereng menunjukkan bahwa tekanan lereng meningkat sehingga, air dari dalam lereng mengalami rembesan ke luar lereng.

Pengelolaan terkait longsor di Desa Sumberharjo, Kecamatan Prambanan, Kabupaten Sleman, Daerah Istimewa Yogyakarta berdasarkan Peraturan Menteri PU Nomor 22/PRT/M/2007 tentang Pedoman Penataan Ruang Kawasan Rawan Bencana Longsor menggunakan beberapa pendekatan yaitu pendekatan rekayasa teknis, pendekatan sosial, dan pendekatan institusi. Arahan pengelolaan disesuaikan dengan tata ruang wilayah Desa Sumberharjo yang diperuntukan sebagai permukiman pedesaan, pertanian, dan perkebunan. Upaya pengendalian longsor yang disarankan menurut Pedoman Departemen Pekerjaan Umum Pd T-09-2005-B tentang Rekayasa Penanganan Keruntuhan Lereng pada Tanah Residual dan Batuan yaitu pembuatan teras dengan konsep perubahan geometri lereng. Sudut kemiringan lereng awal keseluruhan yaitu $40^{\circ}$ dilakukan pemotongan lereng dan penimbunan lereng menjadi $45^{\circ}$ pada bagian kepala lereng dan $20^{\circ}$ pada bagian kaki lereng. Perbedaan pembentukan sudut lereng dikarenakan keterbatasan keleluasaan pemotongan akibat dari adanya bangunan di atas lereng yang memiliki jarak 8 meter dari kepala lereng, sehingga dengan sudut potong $45^{\circ}$ diasumsikan tidak mengubah kondisi awal bangunan di atas lereng. Terasering yang dilakukan di bagian kepala lereng memiliki tinggi teras 11.3 meter dan bidang olah teras memiliki lebar 12 meter sedangkan, teras yang dibuat di bagian kaki lereng memiliki 
tinggi teras meter dan lebar bidang olah teras yaitu 20 meter. Pembuatan teras dikombinasikan dengan pembuatan dinding penahan di bagian teras ketiga. Sehingga, upaya tersebut meningkatkan faktor keamanan menjadi 1.33 dengan klasifikasi stabil.

Pembuatan teras juga dikombinasikan dengan pembuatan saluran drainase. Tujuan pembuatan saluran drainase yaitu mengurangi jumlah air hujan yang menjadi aliran rembesan ke dalam tanah agar tidak menjenuhkan tanah pada lereng. Dimensi drainase horizontal terdiri dari lebar bawah saluran (b) yaitu 123, lebar atas saluran (B) yaitu 123, dan tinggi saluran (h) yaitu 123. Dimensi drainase vertikal terdiri dari lebar bawah saluran (b) yaitu 123, lebar atas saluran (B) yaitu 123, dan tinggi saluran (h) yaitu 123. Upaya tambahan untuk memperkuat lereng yaitu dilakukan rekayasa vegetatif dengan penanaman pohon jati dengan kombinasi rumput akar wangi. Penanaman pohon jati menggunakan sistem pot dengan jarak $6 \mathrm{~m} \times 6 \mathrm{~m}$ pada teras yang disesuaikan dengan ukuran bidang olah.

\section{KESIMPULAN}

Tingkat kerawanan longsor di daerah penelitian terbagi menjadi 3 kelas yaitu tingkat kerawanan rendah, kerawanan sedang, dan kerawanan tinggi. Ketiga zona memiliki faktor pemicu berupa curah hujan. Zona kerawanan tinggi dikontrol oleh tekstur tanah, infiltrasi, penggunaan lahan, dan kekar dan didukung dengan nilai faktor keamanan lereng lahan sisa longsor yaitu 0.94 yang termasuk ke dalam klasifikasi tidak stabil. Teknik rekayasa dalam pengendalian longsor di daerah penelitian dilakukan dengan pembuatan teras, pembuatan dinding penahan tanah, pembuatan saluran drainase permukaan, dan rekayasa vegetatif dengan penanaman kombinasi pohon jati dan rumput akar wangi dilakukan sebagai kombinasi rekayasa untuk meningkatkan lereng menjadi stabil dengan nilai faktor keamanan yaitu 1.33.

\section{DAFTAR PUSTAKA}

Departemen Pekerjaan Umum. 2005. Pedoman Konstruksi dan Bangunan

Dibyosaputro. 1998. Longsor Lahan di Daerah Kecamatan Samigaluh Kabupaten Kulon Progo

Daerah Istimewa Yogyakarta, Laporan Penelitian, Lembaga Penelitian UGM, Yogyakarta.

Karnawati, D. 2005. Bencana Alam Gerakan Massa Tanah di Indonesia dan Upaya Penanggulangannya. Jurusan Teknik Geologi, Fakultas Teknik, Universitas Gadjah Mada, Yogyakarta.

Hunt, E. Roy. 2007. Geologic Hazards A Field Guide for Geotechnical Engineers. CRC Taylor \& Francis Group, New York.

Rahman, MD. Zillur. 2012 Slope Stability and Road Safety Evaluation, (Master's Thesis Division of Mining \& Geotechnical Engineering., Departemen of Civil, Environmental and Natural Resources Engineering). Lulea University of Technology (LTU), Lulea, Sweden.

Zakaria, Zulfiadi. 2009. Analisis Kestabilan Lereng Tanah. Jurusan Teknik Geologi UNPAD, Bandung. 